\title{
Desempenho Econômico do Rio de Janeiro: Trajetórias Passadas e Perspectivas Futuras*
}

\author{
Lia Hasenclever ${ }^{1}$ \\ Julia Paranhos ${ }^{2}$ \\ Ricardo Torres ${ }^{3}$
}

${ }^{1}$ Professora Associada do Instituto de Economia, da Universidade Federal do Rio de Janeiro (UFRJ). E-mail: lia@ie.ufrj.br

${ }^{2}$ Professora Adjunta do Instituto de Economia, da Universidade Federal do Rio de Janeiro

(UFRJ). E-mail: juliapararanhos@ie.ufrj.br

${ }^{3}$ Professor Assistente na Universidade Federal Fluminense (UFF). E-mail:

ricardo.torres@ie.ufrj.br

\section{INTRODUÇÃO}

$\mathrm{O}$

Brasil vivenciou um longo período de crescimento acelerado entre as décadas de 1950 e 1970. Nas décadas de 1980 e 1990, registraram-se, de um lado, profundas modificações na forma de intervenção do Estado, rápido processo de abertura comercial e de desregulamentação econômica, bem como privatizações e, de outro, um rápido processo de modernização tecnológica das empresas por meio da introdução de máquinas e equipamentos importados e profundas transformações organizacionais. Entretanto, não se verificou o mesmo dinamismo de crescimento observado nas duas décadas anteriores. Essas mudanças organizacionais e de modernização e o baixo crescimento econômico registrado no período resultaram em uma mudança estrutural significativa na produção brasileira construída durante as décadas de crescimento acelerado.

A partir de 1996, o Brasil prospera a taxas crescentes, e novos investimentos lideram as perspectivas de crescimento do país, concentrado nos setores industriais e de infraestrutura, e despertam interesses e

\footnotetext{
* Este artigo foi, originariamente, apresentado no Seminário "Juventude, Desigualdades e o Futuro do Rio de Janeiro", realizado na Casa de Rui Barbosa, em junho de 2011, como parte das atividades do Programa de Apoio a Núcleos de Excelência (Pronex), sediado no Instituto de Estudos Sociais e Políticos (IESP), da Universidade do Estado do Rio de Janeiro (UERJ).
}

DADOS - Revista de Ciências Sociais, Rio de Janeiro, vol. 55, n³ 3, 2012, pp. 681 a 711. 
possibilidades distintas de diversificação em cada Estado da federação. No estado do Rio de Janeiro (ERJ), os investimentos em indústria extrativa de petróleo e gás são privilegiados pelo fato de as maiores bacias de reservas de petróleo terem sido descobertas no Rio. Além destes, destacam-se os seguintes investimentos em curso em indústrias com antigas tradições e encadeados com a indústria petrolífera: siderurgia, petroquímica, energia e indústria naval. Os investimentos em infraestrutura são outra frente importante de novos investimentos impulsionados pelas preparações olímpicas a serem sediadas no Rio de Janeiro: transporte público, portos, infraestrutura urbana, e rodovias (BNDES, 2011a; 2011b). Somam-se a esses investimentos concentrados em indústria produtora de bens intermediários e infraestrutura novos investimentos que representam uma diversificação na direção de indústrias do conhecimento, como é o caso, dos centros de pesquisa (expansão do Centro de Pesquisas da Petrobras e parque tecnológico da Universidade Federal do Rio de Janeiro - UFRJ).

As transformações estruturais vivenciadas pela economia brasileira podem ser caracterizadas por três forças interdependentes: (1) um movimento duplo de desconcentração industrial das metrópoles para o interior e de crescimento da importância das regiões metropolitanas na atração de novos investimentos da economia do conhecimento; (2) o crescimento de um setor emergente e dinâmico de serviços produtivos, aqueles de apoio direto à produção (tais como serviços financeiros, jurídicos, de informática, de pesquisa, de engenharia, de consultoria, de propaganda e marketing, de seguro e de auditoria), devido às novas formas de organização da produção trazidas pelo paradigma da microeletrônica e pelas tecnologias de informação e comunicação; (3) e, finalmente, as vantagens das metrópoles como espaços de diversificação das atividades produtivas, ou seja, lugares onde se criam outras atividades com base nas atividades preexistentes.

Estas três forças influenciaram da mesma forma a transformação da economia fluminense, mas trouxeram problemas e desafios distintos. A desconcentração relativa para o interior, em razão do crescimento da indústria do petróleo e gás, por um lado, e, por outro, a dinamização de indústrias metalúrgicas, petroquímica e naval na metrópole e em seu entorno resultaram na mesma tendência da economia brasileira de desconcentração relativa apontada por Diniz (1993, 2000 e 2002) e Hasenclever e Maeda (2007). A localização da indústria petrolífera em Campos e Macaé, cidades com outras tradições econômicas e distantes 
do Rio capital, colocam em evidência as dificuldades de se dinamizar o crescimento. A grande heterogeneidade entre os novos investimentos e as economias locais, despreparadas logisticamente para recebê-los e sem capacidade industrial e tecnológica para participar em complementaridade a eles, é o novo desafio da economia fluminense. Diferentemente, a desconcentração da indústria para o interior de São Paulo encontrou uma infraestrutura logística muito mais preparada e a presença de cidades médias que não deixavam a desejar em urbanidades comparativamente à capital paulista.

Em relação à segunda força mencionada - mudança tecnológica e organizacional viabilizada pelos avanços no paradigma da microeletrônica e informática, que levam ao surgimento de um setor de serviços dinâmicos (Kon, 2004) e que, no Brasil, foi acelerada pela abertura econômica - esta foi aproveitada, na economia brasileira, com a construção de numerosas incubadoras dedicadas à criação de empresas de biotecnologia e informática em São Paulo e seu entorno e no eixo que vai de Belo Horizonte a Porto Alegre. Já o Rio de Janeiro, com a mudança da capital para Brasília, atrasou a definição de uma nova estratégia para a retomada do crescimento da metrópole. Em decorrência disso, perdeu muito espaço no aproveitamento dos setores de serviços mais dinâmicos e associados ao desenvolvimento industrial. Como consequência, o setor de serviços fluminense se concentra mais na prestação de serviços às famílias. Reforça esta dificuldade o longo período em que o Rio ficou conhecido como um local de violência, ambiente econômico burocrático, avesso a novos negócios e não atraiu novos investimentos (The Economist, 2011).

A terceira força apontada para explicar em parte as transformações estruturais é o fato de as metrópoles serem promotoras da diversificação produtiva, seja pelo incremento sistemático de novos bens e serviços a partir da diversidade dos já existentes, seja pelo fato de o lançamento de inovações demandarem uma série de serviços de infraestrutura tecnológica só disponível nas metrópoles (Jacobs, 1970 e 1984). Entretanto, o Rio também permaneceu longo tempo sem um ambiente que valorizasse o seu capital intelectual, representado pelo grande número de universidades e centros de pesquisas aqui localizados e pelo expressivo número de estudantes de graduação e pós-graduação. Só mais recentemente tem se pensado em estratégias para sua absorção (Urani, 2008). 
A questão que importa responder é em que medida estes novos investimentos serão capazes de reverter a trajetória de desenvolvimento medíocre apresentada pelo ERJ no período entre 1996 e 2009 (Fauré e Hasenclever, 2005; Fauré, Hasenclever e Silva Neto, 2008). Um período de crescimento instável até 2004 e uma retomada do crescimento a partir deste ano, mas com uma inflexão em 2009 provocada pela crise internacional de setembro de 2008.

Seriam as transformações estruturais da economia brasileira e aquelas particulares do estado do Rio de Janeiro capazes de romper a sua trajetória de estagnação? Ou as potencialidades do ERJ o levam a prosseguir em sua trajetória de crescimento menos dinâmico em vez de libertá-lo para novas vocações? Em que medida o peso da metrópole fluminense na economia do estado e as características de baixa qualidade do seu setor de serviços impedem a ancoragem de atividades de maior valor agregado no ERJ e reforçam a sua especialização em indústrias produtoras de bens intermediários? A resposta a estas questões será desenvolvida por meio do método comparativo para marcar a evolução e as mudanças ocorridas no estado de Rio frente a outras duas economias: a brasileira e a paulista, utilizando dados secundários do Produto Interno Bruto (PIB) e das pesquisas econômicas sobre a indústria, serviço e comércio, todos produzidos pelo Instituto Brasileiro de Geografia e Estatística (IBGE), e literatura disponível sobre o tema.

O artigo está dividido em três seções, além desta introdução e da conclusão. A primeira mostra a evolução da economia fluminense ante as economias brasileira e paulista, entre 1996 e 2008, destacando suas principais mudanças estruturais em relação à participação dos setores de atividade econômica. A segunda seção traz indicadores de desempenho econômico e de emprego das atividades industrial, de serviços e de comércio, com o fim de identificar quais os setores de cada atividade econômica mais contribuem para explicar as mudanças estruturais observadas na primeira seção. A terceira apresenta uma visão conjuntural após 2007, para verificar se as trajetórias observadas são confirmadas e se há novas perspectivas em curso ainda não refletidas nas pesquisas de dados secundários do IBGE. Finalmente, na conclusão, especula-se com a possibilidade de o Rio de Janeiro adotar novas trajetórias de crescimento que dinamizem o seu desempenho em termos de setores capazes de gerar maior valor agregado e empregos de mais altos salários. 


\section{A ECONOMIA FLUMINENSE FRENTE AS ECONOMIAS BRASILEIRA E PAULISTA}

A evolução comparada da atividade econômica fluminense e dos grandes setores de atividade do ERJ com as economias paulista e brasileira, entre 1996 e 2008, será feita através da exploração dos dados do IBGE sobre o PIB.

Constata-se que, no período entre 1996 e 2008, a parte relativa do ERJ na criação da riqueza nacional, mensurada pelo PIB a preços básicos de 1995, permaneceu relativamente estável e em torno de $11 \%$. Comparando-se com o período entre 1985 e 2001, analisado por Fauré e Hasenclever (2005), isto representa uma queda de um ponto percentual (p.p.) na participação relativa do Estado na economia brasileira, em relação ao período anterior (cerca de $12 \%$ ). Os principais dados que revelam esta tendência de enfraquecimento da atividade econômica fluminense no longo prazo e de estagnação relativa serão apresentados adiante, comparando-se o desempenho do ERJ com o do Brasil e de São Paulo.

O intervalo de 13 anos, entre os anos 1996 e 2008, para o Brasil, pode ser caracterizado por três ciclos de crescimento (ver Gráfico 1): o primeiro, um ciclo de crescimento moderado de quatro anos até 1998, seguido do segundo ciclo, também de crescimento, mas caracterizado por uma maior instabilidade entre 1999 e 2003, e o terceiro, caracterizado por um ciclo de crescimento mais vigoroso e estável entre 2004 e 2008 (cinco anos). De uma forma geral, pode-se observar uma oscilação bastante grande das taxas de crescimento no período, mas o importante a reter é que os ciclos vão aumentando as suas taxas médias de crescimento $(1,4 \%, 2,4 \%$ e $4,8 \%)$, mostrando um período de sustentabilidade ainda que a taxas moderadas. De fato, em 1997, ano de pico de crescimento do primeiro ciclo, o Brasil cresceu a 3,4\%. Em 2000, a taxa máxima de crescimento do segundo ciclo alcançou $4,3 \%$, e, em 2007, terceiro ciclo de crescimento, atingiu $6,1 \%$, enquanto a China, por exemplo, apresentava uma taxa média de crescimento de cerca de $9 \%$.

O desempenho do PIB do Rio de Janeiro (ver Gráfico 1) foi menos virtuoso do que o brasileiro, já que apresentou, nos três ciclos, taxas médias de crescimento inferiores às nacionais. O ponto de inflexão mais baixo do período é registrado em 2003, e não em 1998, como na economia brasileira, e é bem mais intenso (crescimento negativo de 1,1\%) do que o do Brasil. O período entre 1996 e 2008 caracteriza-se, da mesma forma, por três ciclos de crescimento com taxas médias crescentes: 0,8\% entre 
1996 e 1999, 1,5\% entre 2000 e 2003 e 3,6\% entre 2004 e 2008. É também no segundo ciclo que se observa a maior instabilidade das taxas de crescimento.

Já o PIB do estado de São Paulo (ver Gráfico 1), no mesmo período, apresentou um desempenho, mensurado pelas taxas médias de cresci-

Gráfico 1

Taxa de Crescimento Anual do PIB Brasileiro, Fluminense e Paulista e Ciclos (1996-2008)
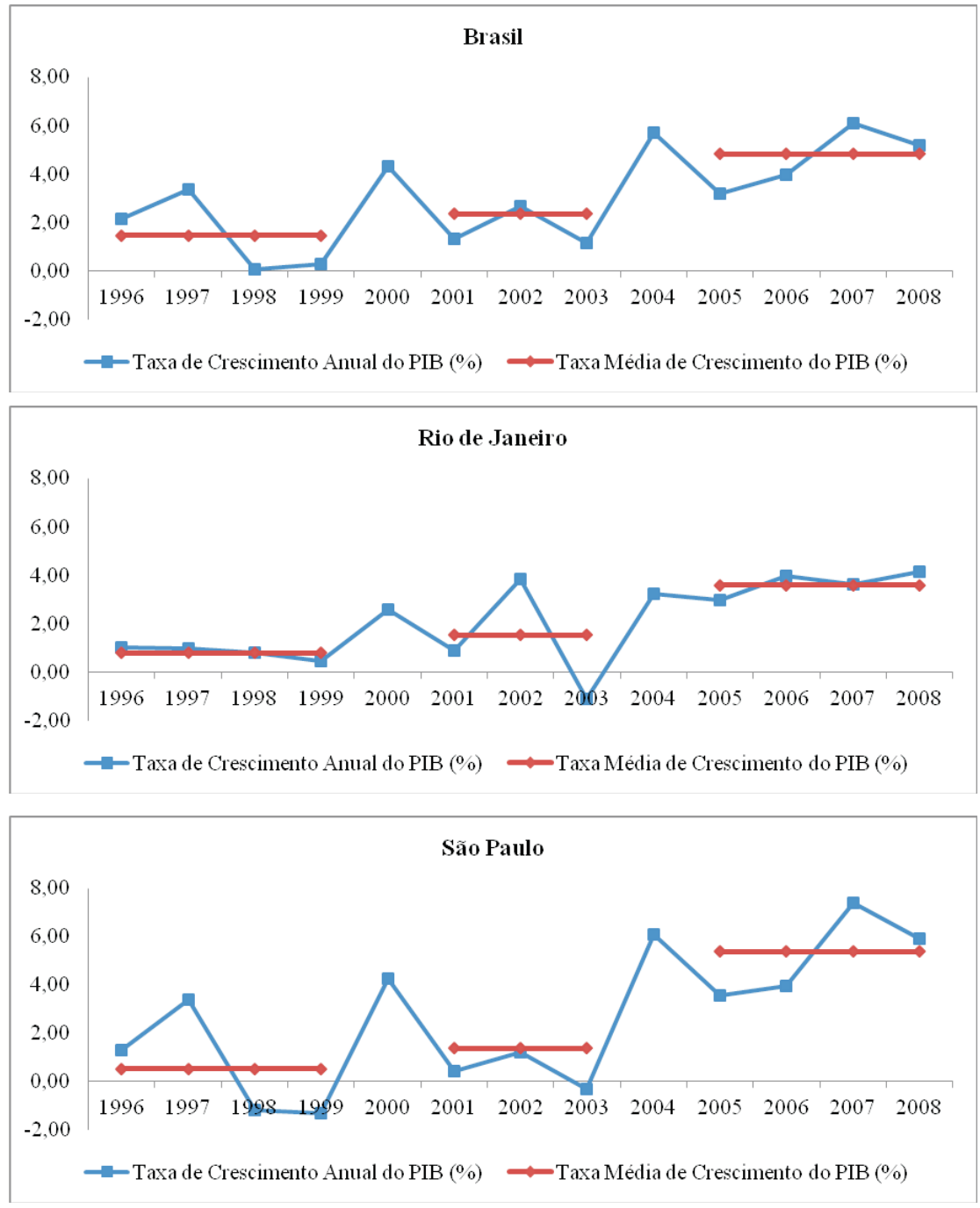

Fonte: Elaborado pelo Grupo de Economia da Inovação (IE/UFRJ) com base na Retropolação das Contas Nacionais e Regionais, IBGE (1996-2008). 
mento, inferior ao do Rio de Janeiro nos dois primeiros ciclos, mas superior aos desempenhos do Brasil e do Rio no terceiro ciclo. Pode-se explicar este desempenho pelo fato de o estado paulista apresentar as mais altas taxas de inflexão negativas do período: em 1998, 1,2\% negativa, em 1999, 1,3\% negativa e em 2003, 0,4\% negativa. Este comportamento mais instável da economia paulista reflete em grande medida as flutuações mais violentas que a indústria costuma ter durante os ciclos econômicos, já que a sua capacidade de encadeamento produtivo é maior do que a dos outros setores de atividade. Assim, os períodos de declínio e também os de boom são mais intensos.

Tomando-se o ano-base de 1996, a indústria de transformação do ERJ apresenta um crescimento acumulado negativo de $15,4 \%$, entre 1996 e 2008 , contra um crescimento acumulado positivo de $28,3 \%$ do país e de $20 \%$ no estado de São Paulo (ESP). A indústria extrativa fluminense, entretanto, mostra o seu pleno vigor: taxa acumulada de crescimento de $173 \%$, no mesmo período, enquanto a indústria extrativa brasileira acumulava um crescimento de $77,3 \%$ e a indústria extrativa paulista encolhia em 7,1\%. A indústria geral, entretanto, tem um melhor desempenho neste período no Brasil, com taxa média de crescimento anual de 2,3\%, e em São Paulo (média de 1,6\% ao ano) do que no Rio (média de $1 \%$ ao ano). Os serviços e o comércio do Rio de Janeiro, por sua vez, acumularam um crescimento de respectivamente $35,4 \%$ e $15,6 \%$. Flagrantemente inferior ao crescimento acumulado no mesmo período pelo Brasil e por São Paulo (respectivamente de 48,8\% e 42,9\% para o primeiro e $46,9 \%$ e $38,9 \%$ para o segundo).

O resultado destes distintos desempenhos dos PIBs do Brasil, do Rio de Janeiro e de São Paulo, no período 1996-2008, leva a alterações nas participações relativas dos PIBs dos estados no PIB brasileiro: o Rio perde 0.1 p.p. e São Paulo 3.4 p.p. de participação relativa. Ou seja, o fato de que o ESP tenha apresentado um desempenho mais instável ao longo do período levou à perda de sua participação relativa na economia brasileira maior do que a do ERJ. Entretanto, sua taxa de crescimento médio no período foi superior em 0.5 p.p. à do ERJ (respectivamente, $2,6 \%$ e $2,1 \%$ ) e ambas foram menores do que a taxa de crescimento média brasileira $(3,0 \%)$, refletindo o transbordamento do crescimento para o interior do Brasil. A semelhança das duas unidades federativas em foco está na perda de participação relativa no PIB brasileiro, sendo que este fenômeno foi bastante mais significativo para o ESP. 
O exame das participações relativas por setores de atividade econômica - agropecuária, indústria e serviços - de cada estado da federação no PIB brasileiro setorial (ver Tabela 1) leva a concluir pelos seguintes traços principais no estado fluminense: a agropecuária, que, em 1996, representava apenas cerca de 1,4\% do PIB agropecuário brasileiro, perde cerca de $40 \%$ de sua importância, passando a representar $0,8 \%$, em 2008; a indústria, que representava $8,6 \%$ da indústria brasileira, aumentou para $12,7 \%$, refletindo principalmente o crescimento da indústria extrativa; a atividade de serviços, por sua vez, reduziu sua importância de $13 \%$ para $11,6 \%$; as perdas relativas nesse setor são generalizadas, mas mais intensas no subsetor financeiro e em atividades de administração em saúde e educação pública e seguridade social, denominadas APU (perda de cerca de 2 p.p. em cada um deles).

Tabela 1

Participação (\%) das Economias Fluminense e Paulista por Atividade Econômica em Valor Adicionado Bruto a Preço básico no Brasil

(1996 e 2008)

\begin{tabular}{l|c|c|c|c}
\hline Atividade Econômica & \multicolumn{2}{|c|}{1996} & \multicolumn{2}{c}{2008} \\
\hline & RJ & SP & RJ & SP \\
\hline Agropecuária & 1,4 & 8,6 & 0,8 & 7,9 \\
Indústria & 8,6 & 42,9 & 12,7 & 33,9 \\
Indústria Extrativa Mineral & 18,7 & 5,0 & 53,5 & 1,2 \\
Indústria de Transformação & 6,3 & 46,8 & 6,7 & 43,7 \\
Construção & 13,9 & 36,5 & 10,6 & 27,6 \\
SIUP* & 8,2 & 45,4 & 6,0 & 25,6 \\
Serviços & 13,0 & 34,9 & 11,6 & 33,4 \\
Comércio & 8,4 & 41,3 & 8,3 & 31,2 \\
Financeiro & 10,7 & 49,9 & 8,8 & 51,1 \\
APU** & 14,7 & 20,9 & 12,7 & 19,0 \\
Outros & 14,2 & 35,7 & 12,9 & 37,7 \\
\hline Total & $\mathbf{1 1 , 2}$ & $\mathbf{3 5 , 6}$ & $\mathbf{1 1 , 2}$ & $\mathbf{3 2 , 0}$ \\
\hline
\end{tabular}

Fonte: Elaborado pelo Grupo de Economia da Inovação (IE/UFRJ) com base na Retropolação das Contas Nacionais e Regionais, IBGE.

Nota: Preço básico em R\$ de 1995.

* Produção e distribuição de eletricidade e gás, água, esgoto e limpeza urbana.

** Administração, saúde e educação públicas e seguridade social.

No estado paulista, o peso da agropecuária no PIB brasileiro, em 2008, permanece relativamente estável, em torno de 7,9\% (em 1996, era de $8,6 \%)$; a indústria perde participação relativa de 9 p.p., passando de 
42,9\% do PIB brasileiro para 33,9\% entre 1996 e 2008. A perda da participação da indústria paulista no PIB industrial brasileiro deve-se principalmente à indústria extrativa (-3.8 p.p.) e à indústria de transformação (-3.1 p.p.). Os serviços também perdem em participação: em 1996, representavam $34,9 \%$ e, em $2008,33,4 \%$ (perda de 1.5 p.p.). O resultado é decorrente, por um lado, dos ganhos relativos apresentados pelo setor financeiro (melhora de 1.3 p.p.) e, por outro lado, da perda relativa do comércio paulista no comércio brasileiro (perda de 10.1 p.p.).

Esta abordagem da participação relativa pode ser complementada pela evolução da estrutura produtiva setorial em cada unidade de análise: Brasil, ERJ e ESP. No Brasil, como era de se esperar, observa-se uma maior estabilidade nas participações dos setores de agropecuária, indústria e serviços no período entre 1996 e 2008. De fato, elas se situam em torno de, respectivamente, 6\%, 28\% e 66\% em 2008. Em 1996, a indústria era um pouco menos importante, e o setor de serviços, mais representativo, respectivamente $25 \%$ e $68 \%$.

No ERJ, diferentemente, notam-se mudanças estruturais, mensuradas pela participação relativa de cada setor ao longo do período, bastante significativas. A importância relativa da agricultura no PIB fluminense, que já era diminuta e inferior a $1 \%$, reduziu-se muito mais, passando de $0,7 \%$ para $0,4 \%$ (redução de cerca de $50 \%$ ). A participação relativa da indústria cresceu significativamente, de 19,9\%, em 1996, para $31,6 \%$, em 2008 (crescimento de quase $60 \%$ no período). Finalmente, a importância relativa do setor de serviços, tradicionalmente relevante na economia fluminense e próxima de $80 \%$, em 1996, retroagiu a cerca de $68 \%$, em 2008.

No ESP, ainda que tenha havido mudanças, elas se mostram menos pronunciadas. De fato, a participação relativa do setor agropecuário passa de 1,3\% para 1,5\%; a indústria perde participação relativa no PIB paulista, mas apenas de 1.9 p.p.; o setor de serviços ganha participação relativa de 1.7 p.p.

Comparando-se as estruturas setoriais dos dois estados da federação com a do Brasil, a maior diferença das participações relativas setoriais diz respeito ao peso relativo da agropecuária, que, mesmo sendo mais relevante no PIB paulista, não ultrapassa o peso relativo de 1,5\%, enquanto, no Brasil, esta participação setorial representa cerca de $6 \%$, tendo crescido 0.5 p.p. entre 1996 e 2008. Em compensação, os pesos re- 
lativos da indústria e dos serviços, tanto do Rio de Janeiro, quanto de São Paulo, são superiores aos pesos relativos desses setores no Brasil. A importância dos setores industrial e de serviços nos dois estados é, por um lado, herança do período de industrialização das décadas de 1950 a 1970, que se iniciou pelo sudeste, e, por outro, decorrente das duas metrópoles conurbadas pela concentração industrial. No Rio, pode-se acrescer a importância da localização da capital do Brasil, até 1960, e de grande parte das empresas públicas, até 1990, fatos que fortaleceram a importância do setor de serviços neste estado até as datas mencionadas.

Enfim, percebe-se claramente que as mudanças estruturais foram mais intensas no ERJ, mas não parecem apresentar o mesmo dinamismo em termos de taxa de crescimento que o apresentado pelo Brasil e por São Paulo, no período analisado. A título de sumariar esta seção, observa-se que o ERJ apresenta, em relação ao Brasil e ao ESP, duas grandes diferenças. A primeira é o fato de o ERJ ter que se reestruturar em função da perda da capital, deixando de ser uma metrópole especializada em serviços para a administração pública e centro logístico de comércio atacado, e a segunda é que as novas ondas de investimento, na metrópole e no interior, são ainda indústrias baseadas na exploração de recursos naturais e produtoras de bens intermediários. Os desafios e problemas que esse menor dinamismo da economia fluminense apresenta serão aprofundados na próxima seção.

\section{INDICADORES DE DESEMPENHO E EMPREGO DAS ATIVIDADES ECONÔMICAS INDUSTRIAL, DE SERVIÇOS E DE COMÉRCIO FLUMINENSE COMPARADOS COM OS DO BRASIL E DE SÃO PAULO}

Nesta seção, realizou-se a análise em separado de cada pesquisa secundária utilizada (Pesquisa Industrial Anual - PIA, Pesquisa Anual de Serviços - PAS e Pesquisa Anual do Comércio - PAC). Este procedimento justifica-se pelo fato de não poderem ser somadas em razão das distintas amostras consideradas em cada uma delas. O exame dos indicadores de desempenho econômico e emprego foi feito considerando-se a sua evolução no Brasil, no ERJ e no ESP e, a seguir, compararam-se as três economias. O período considerado para análise é distinto por pesquisa do IBGE e está informado em cada uma das três subseções em que se divide esta seção. 


\section{Evolução Absoluta e Comparativa da Composição Setorial da Indústria: 1996-2007}

A indústria geral, no período 1996-2008, do Brasil e de São Paulo mostrou, pelas estatísticas do PIB por setores de atividade, um crescimento acumulado positivo, respectivamente de $34 \%$ e $23 \%$, enquanto a indústria geral do Rio de Janeiro mostrou uma taxa de crescimento acumulado bem inferior de 14\%. Em suma, as taxas de crescimento acumuladas no período mostram um dinamismo maior para o Brasil e para São Paulo. A seguir apontam-se três razões para explicar o menor dinamismo da economia fluminense.

A primeira razão é o peso relativo maior da indústria extrativa, por ser esta atividade sabidamente menos importante na criação de riqueza pelo seu baixo grau de agregação de valor. De fato, a atividade industrial pode ser dividida em indústria extrativa e de transformação. A primeira pode ser subdividida em quatro subdivisões ou setores, e a segunda, em 23 setores. Os dados de Valor Bruto da Produção Industrial (VBPI), fornecidos pela PIA de 1996 a 2007, mostram que a indústria de transformação tem um peso relativo muito maior na geração de valor nas economias brasileira e paulista (95\% e $99 \%$ em 2007), mas tem um peso menor na indústria fluminense (79\% em 2007). Essa divisão estrutural da indústria deve-se essencialmente à relevância do setor de extração de petróleo e serviços relacionados no Rio de Janeiro, classificado como indústria extrativa.

A segunda razão para o baixo dinamismo do PIB fluminense pode ser atribuída à mais alta taxa de concentração dos setores industriais fluminenses e ao tipo de indústria predominante no Estado. Com efeito, ainda que a indústria como um todo seja bastante concentrada em todas as três economias, em 2007, sendo os quatro maiores setores responsáveis pela geração de mais de $49 \%$ do VBPI, a indústria do Rio é a mais concentrada das três economias, seguindo-se o ESP e o Brasil. Os três principais setores em termos de geração de VBPI no Brasil e no ESP eram os mesmos (alimentos e bebidas; produtos químicos; montagem de veículos automotores, reboques e carrocerias). O quarto setor no Brasil era metalurgia básica, e no ESP, máquinas e equipamentos. Já no ERJ, os dois maiores setores eram petróleo e serviços relacionados e refino de petróleo, álcool e outros. O terceiro mais importante era metalurgia básica, setor também presente no Brasil, e o quarto, produtos químicos, setor também presente no Brasil e no ESP. 
Quanto ao tipo de indústria por categoria de uso que predomina em cada economia, considerando-se o valor de transformação industrial, percebe-se nitidamente que a economia fluminense tem uma alta concentração nas indústrias produtoras de bens intermediários $(76,7 \%)$, enquanto no Brasil e em São Paulo elas alcançam 54,7\% cada uma. O peso maior da indústria de bens intermediários traz menor dinamismo interno à economia fluminense, que é altamente dependente de outras economias.

A terceira e última razão seria a maior instabilidade cíclica na evolução do VBPI no período 1996-2007. A indústria no Brasil, no Rio e em São Paulo apresenta ciclos de crescimento bastante semelhantes: conjuntura recessiva nos anos de 1999 e 2002 e picos de crescimento em 2000 e 2003. Entretanto, nos ciclos recessivos, o Rio de Janeiro apresentou as menores taxas negativas e, nos ciclos de crescimento, as maiores taxas positivas.

Esta maior instabilidade cíclica é reforçada pelo crescimento menos vigoroso do pessoal ocupado (PO) no Rio. A evolução do indicador PO para as três economias é negativa até 1998. A partir deste ponto, as economias se diferenciam: o Brasil entra em rota de crescimento do PO até 2007, enquanto o ERJ apresenta uma trajetória mais cíclica, no que é seguido pelo ESP. As menores taxas de crescimento de PO, no período, são registradas para o ERJ, exceto para o ano de 2006.

Em termos de taxas de crescimento, entre 1996 e 2007, a indústria fluminense cresce a uma taxa média anual do VBPI superior às observadas nas indústrias brasileira e paulista (3,3\% contra, respectivamente, $3,1 \%$ e $1,4 \%$ ), acumulando um crescimento de $43 \%$ contra $40,5 \%$ da indústria brasileira e $17 \%$ da indústria paulista. A taxa média de crescimento anual do PO na indústria geral, entretanto, é zero para o Rio de Janeiro e positiva para o Brasil e São Paulo (3,2\% e 1,7\% respectivamente).

Os maiores dinamismos do crescimento industrial brasileiro e fluminense devem-se ao estrondoso crescimento da indústria extrativa no período, que cresceu em média 9,5\% a.a. no Brasil e 14\% a.a. no Rio de Janeiro. A indústria de transformação, por sua vez, exibe a melhor taxa média de crescimento para o Brasil (média de 2,9\% a.a.). Rio e São Paulo apresentam taxas médias anuais de $1,8 \%$ e 1,5\%, respectivamente, resultando em um crescimento acumulado de $37 \%$ para o Brasil, 21,2\% para o Rio de Janeiro e 17,2\% para São Paulo. Este maior dinamismo do 
crescimento da indústria extrativa no Rio, todavia, não foi capaz de gerar uma taxa de crescimento do PO positiva no conjunto da indústria $(0 \%)$. De fato, enquanto a taxa média anual de crescimento do PO na indústria extrativa foi de $8,2 \%$, a da indústria de transformação foi negativa em $0,4 \%$.

As estruturas das indústrias brasileira, paulista e fluminense em função das distintas taxas de crescimento, em termos de VBPI, entre $1996 \mathrm{e}$ 2007, foram alteradas em termos de subsetores (ver Tabela 2): de um lado, um crescimento da participação relativa da indústria extrativa no Brasil bastante modesto (2.5 p.p.), um crescimento do peso relativo da indústria extrativa fluminense de 14 p.p. e uma redução de 0.1 p.p. da participação relativa da indústria extrativa na indústria paulista. Por outro lado, a participação relativa da indústria de transformação, que representava $97,4 \%$ da indústria brasileira, caiu para $95 \%$; para o Rio de Janeiro, a perda da participação da indústria de transformação na indústria fluminense foi muito superior, caindo de $93 \%$ para $79 \%$; finalmente, a participação relativa da indústria de transformação na indústria paulista manteve-se praticamente estável (de 99,6\% para $99,7 \%)$.

Tabela 2

Estrutura da Indústria Brasileira, Fluminense e Paulista por Subsetores (\%): VBPI e PO, 1996 e 2007

\begin{tabular}{|c|c|c|c|c|c|c|c|c|c|c|c|c|}
\hline \multirow{3}{*}{ Subsetores } & \multicolumn{4}{|c|}{ Brasil } & \multicolumn{4}{|c|}{ Rio de Janeiro } & \multicolumn{4}{|c|}{ São Paulo } \\
\hline & \multicolumn{2}{|c|}{ VBPI } & \multicolumn{2}{|c|}{$\mathrm{PO}$} & \multicolumn{2}{|c|}{ VBPI } & \multicolumn{2}{|c|}{\begin{tabular}{|l|}
$\mathrm{PO}$ \\
\end{tabular}} & \multicolumn{2}{|c|}{ VBPI } & \multicolumn{2}{|c|}{$\mathrm{PO}$} \\
\hline & 1996 & 2007 & 1996 & 2007 & 1996 & 2007 & 1996 & 2007 & 1996 & 2007 & 1996 & 2007 \\
\hline $\begin{array}{l}\text { 1. Indústrias } \\
\text { extrativas }\end{array}$ & 2,6 & 5,0 & 2,3 & 2,3 & 7,3 & 21,4 & 3,4 & 8,0 & 0,4 & 0,3 & 0,7 & 0,5 \\
\hline $\begin{array}{l}\text { 2. Indústrias de } \\
\text { transformação }\end{array}$ & 97,4 & 95,0 & 97,7 & 97,7 & 92,7 & 78,6 & 96,6 & 92,0 & 99,6 & 99,7 & 99,3 & 99,5 \\
\hline $\begin{array}{l}\text { Total da } \\
\text { indústria }\end{array}$ & 100 & 100 & 100 & 100 & 100 & 100 & 100 & 100 & 100 & 100 & 100 & 100 \\
\hline
\end{tabular}

Fonte: Elaborado pelo Grupo de Economia da Inovação (IE/UFRJ) com base na Pesquisa Industrial Anual, IBGE (1996-2007).

Em termos de participação relativa do $\mathrm{PO}$ na indústria extrativa e na indústria de transformação, o Brasil não mostrou mudanças estruturais entre 1996 e 2007 ( $2 \%$ contra 98\%), assim como São Paulo (menos de 1 contra 99\%). Entretanto, a mudança estrutural em termos da participação relativa de PO na indústria fluminense foi elevada. Em 1996, a 
indústria extrativa respondia por 3,4\% do $\mathrm{PO}$ e, em 2007, passou a responder por $8 \%$.

O resultado da mudança estrutural mais intensa no ERJ reflete-se na manutenção da contribuição da indústria fluminense na indústria brasileira, no período entre 1996 e 2007, enquanto a menor mudança estrutural no ESP leva à redução da participação relativa da indústria paulista na indústria brasileira. Estes resultados podem ser explicados principalmente pelo crescimento da participação da indústria extrativa fluminense na indústria extrativa brasileira (de 20,4\% para 31,6\%), enquanto a indústria extrativa paulista perdia espaço na indústria extrativa brasileira, passando de 7,2\% para 2,3\%. Com efeito, no período observou-se a manutenção do peso relativo das indústrias de transformação do Rio de Janeiro e de São Paulo na indústria de transformação brasileira, respectivamente, em torno de 6\% e 42\%, em 1996 e 2007.

\section{Evolução Absoluta e Comparativa da Composição Setorial de Serviços: 2002-2007}

Os serviços no período 1996-2008, como já mostrado na análise do PIB, realizada na primeira seção, apresentaram um crescimento positivo tanto para o Brasil quanto para o ERJ e o ESP. O que variou foram as intensidades de crescimento registradas. Enquanto o Brasil e o ESP apresentaram uma taxa acumulada superior a $45 \%$, o ERJ acumulou apenas $35 \%$ de crescimento no período. Este resultado da economia fluminense é menos diferenciado, ainda que inferior, ao crescimento das demais economias, do que o observado no setor industrial.

A atividade de serviços pode ser subdividida em sete atividades principais: serviços prestados às famílias (alojamento e alimentação, atividades recreativas e culturais, serviços pessoais, ensino continuado), serviços de informação e comunicação, serviços prestados às empresas, serviços de transporte (rodoviário, outros, armazenamento e serviços auxiliares de transporte, correio e outras atividades de entrega), atividades imobiliárias e de aluguel de bens móveis e imóveis, serviços de manutenção e reparo, outras atividades de serviços. Estas atividades têm distintos conteúdos tecnológicos e de demanda de mão de obra. As mais intensivas em conteúdos tecnológicos são os serviços de informação e comunicação, serviços prestados às empresas e serviços de transporte. As demais são mais intensivas em utilização de mão de obra. 
O setor de serviços é ainda mais concentrado do que o industrial. As três atividades mais importantes são, em termos de geração de receita bruta de serviços (RBS), os serviços de comunicação e informação, os serviços de transporte e os serviços prestados às empresas, representando mais de $80 \%$ da receita bruta do setor, em 2007, nas três economias analisadas. Em termos de PO, entre as três atividades anteriores mais importantes, observa-se que os serviços prestados às empresas perdem o lugar para os serviços prestados às famílias nas três economias e representam $80 \%$ dos empregos gerados no setor. A única diferença é que o peso relativo dos serviços prestados às famílias na economia fluminense é maior do que nas demais economias.

As três economias, no que diz respeito ao peso destas atividades no setor de serviços, são bastante semelhantes em relação à soma da RBS das três principais atividades. Entretanto, pode-se notar uma ligeira maior importância das atividades de serviços de comunicação e de transportes e serviços auxiliares no ESP em relação ao ERJ. O Brasil apresenta uma maior importância relativa das atividades de transportes e serviços auxiliares.

Além das atividades mais relevantes no setor de serviços, pode-se observar, no ano de 2007, um maior peso da RBS para o setor de serviços prestados às famílias e nas atividades imobiliárias e de aluguel no ERJ, tanto em relação ao ESP, quanto em relação ao Brasil. Mas as diferenças não chegam a representar mais do que um ponto percentual. Entretanto, ainda que as diferenças sejam pequenas, pode-se afirmar que elas espelham bem as características do Rio: uma cidade de lazer (serviços prestados às famílias) e de especulação imobiliária (atividades imobiliárias e de aluguel). Ao contrário de São Paulo, que está mais voltado para as atividades de serviço ligadas às empresas.

A análise da evolução do setor de serviços será feita para o período 2002-2007 a partir de indicadores de desempenho econômico (RBS e PO), segundo dados da PAS. O ano de 2003 é um ano de queda na taxa de crescimento da RBS e PO. Segue-se um ciclo de taxas anuais de crescimento estáveis da RBS cerca de $10 \%$ a.a. para o Brasil e de $11 \%$ a. a. para São Paulo. O Rio apresentou uma taxa anual de crescimento oscilante de sua RBS e bem inferior (em torno de 6\%). O crescimento mais vigoroso do setor de serviços paulista pode ser explicado pelo aumento mais acelerado do número de empresas de serviços (em média, taxa anual de crescimento de $2 \%$ ) do que o da economia brasileira (média de 
$1,5 \%$ a.a.) e o da economia fluminense (média de $0,8 \%$ a.a.). A taxa de crescimento do PO no Rio é a menor entre as três economias, exceto para o ano de 2007.

A taxa de crescimento anual de PO, no período 2002-2007 foi mais acelerada do que a taxa média de crescimento anual do número de empresas e menos acelerada do que a taxa média de crescimento anual da RBS em todas as economias em análise. A taxa média de crescimento anual da RBS foi de cerca de 9\% para o Brasil e São Paulo e apenas de $4,9 \%$ para o ERJ. No fim do período, o Rio de Janeiro havia acumulado apenas metade do crescimento brasileiro e paulista (26\% contra $50 \%$ ). Ou seja, provavelmente devido ao menor peso das atividades de serviços ligadas à indústria, no Rio, a taxa de crescimento da RBS permanece muito aquém dos resultados alcançados pelo Brasil e por São Paulo. Em termos de $\mathrm{PO}$, entretanto, as taxas médias de crescimento do Brasil e do Rio de Janeiro são de $5 \%$ e $4 \%$, respectivamente, enquanto São Paulo cresce apenas a uma taxa média anual de $0,1 \%$. Isto resulta em uma taxa acumulada de crescimento de PO no período de $28 \%$ para o Brasil e 20\% para o Rio, enquanto São Paulo acumulou um crescimento de $\mathrm{PO}$ de apenas $0,3 \%$.

A estrutura do setor de serviços por subsetores, em termos de RBS ficou mais ou menos estável entre 2002 e 2007 (ver Tabela 3). As pequenas mudanças observadas foram redução de um ponto percentual na participação dos serviços prestados à família no Brasil e no estado de São Paulo e uma manutenção do peso destas atividades no Rio de Janeiro. Os serviços de comunicação e informação aumentam o seu peso relativo na economia fluminense, perdem peso relativo na brasileira e se mantêm estáveis na paulista. Os serviços prestados às empresas aumentam seu peso relativo nas três economias (2 p.p. no Brasil e no Rio e 1 p.p. em São Paulo).

Em termos de $\mathrm{PO}$, as mudanças foram mais acentuadas na participação relativa dos setores. A representatividade dos serviços prestados às famílias reduziu-se nas três economias, mas com mais intensidade no Brasil e em São Paulo. Nessas duas economias, a queda da participação relativa dos serviços prestados às famílias foi compensada pelo aumento da participação relativa dos serviços de comunicação e informação e dos serviços prestados às empresas. No Rio de Janeiro, as participações relativas que cresceram no período foram serviços de informação e comunicação, acompanhando as outras duas economias, e ou- 
Tabela 3

Estrutura do Setor de Serviços Brasileiro, Fluminense e

Paulista por Subsetores (\%):

RBS e PO, 2002 e 2007

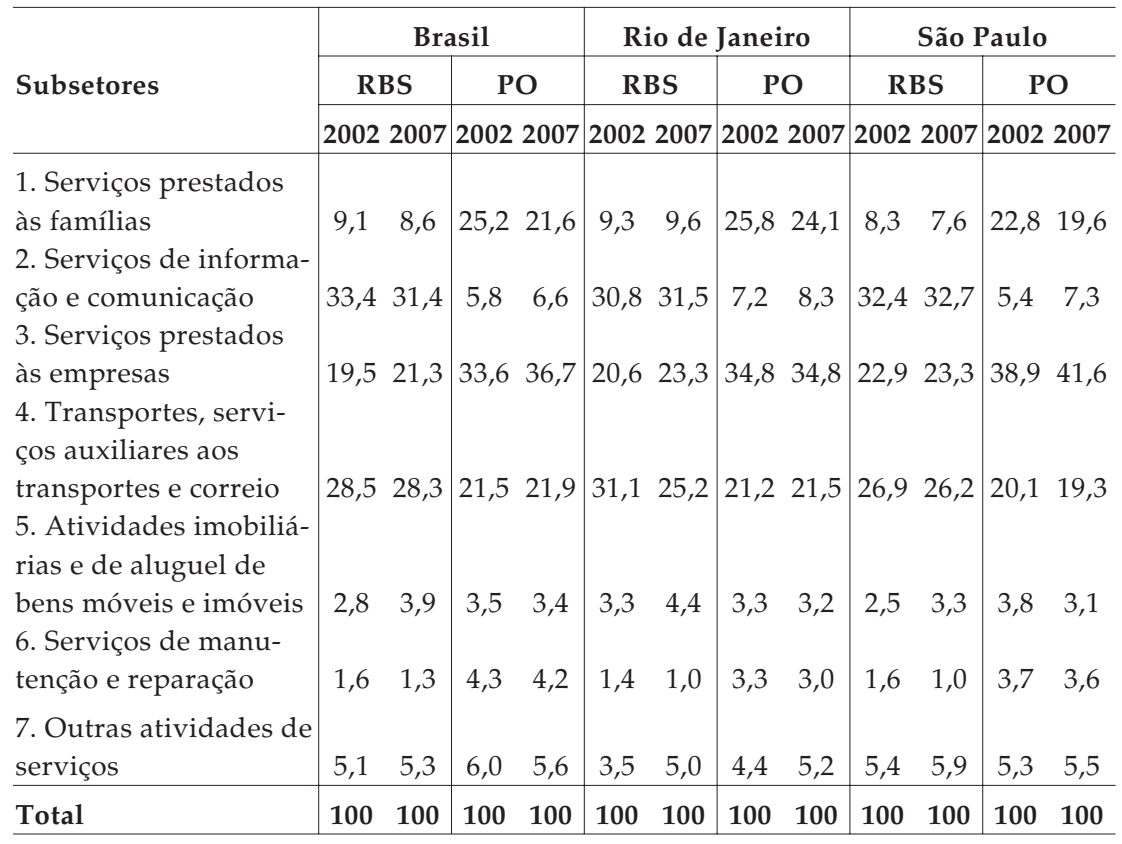

Fonte: Elaborado pelo Grupo de Economia da Inovação (IE/UFRJ) com base na Pesquisa Anual dos Serviços, IBGE $(2002,2007)$.

tras atividades de serviços (composta de serviços auxiliares para agropecuária e reposição florestal e para financiamento de seguro e previdência complementar; esgoto, coleta e disposição de resíduos e recuperação de materiais).

O resultado destes distintos desempenhos das atividades do setor de serviços por estado da federação leva a uma redução do setor de serviços fluminense na criação de riqueza nacional de 2 p.p., passando de uma contribuição ao PIB de serviços brasileiro de 15\%, em 2002, para $13 \%$, em 2007. São Paulo aumenta sua participação na geração de riqueza 1 p.p. (de $42,5 \%$ para $43,3 \%$ do PIB de serviços brasileiro). O desempenho negativo do Rio deve-se a uma perda generalizada nas atividades de serviços. A única atividade que ganha participação do PIB brasileiro de serviços é referente ao item outras atividades de serviços. Entre as atividades mais relevantes do setor de serviços, a maior perda na participação do PIB de serviços brasileiro é em transporte e serviços 
auxiliares (5 p.p.). São Paulo, por sua vez, amplia significativamente as atividades de informação e comunicação.

\section{Evolução Absoluta e Comparativa da Composição Setorial do Comércio: 1996-2007}

A estatística do PIB brasileiro por setor de atividades mostra que o comércio é um dos subsetores dos serviços e, como visto na primeira seção, o comércio fluminense cresceu a uma taxa acumulada, no período entre 1996 e 2008, muito menor do que a metade do que cresceu esta atividade nas economias brasileira e paulista. A PAC é uma pesquisa específica para o setor de comércio com dados disponíveis entre 1996 e 2007. Sua análise, entretanto, se restringirá ao período 2003-2007, dado que em 2003 houve uma mudança na metodologia empregada pelo IBGE e, em vez de ser usada a variável receita bruta de vendas, passou a ser usada a variável receita bruta de revenda (RBR).

Este setor pode ser dividido em três grandes subsetores: comércio de veículos e motocicletas e varejo de combustíveis; comércio por atacado; e comércio varejista. Em 2007, por RBR, a atividade mais relevante para o Brasil e para São Paulo era o comércio por atacado (respectivamente, $44,5 \%$ e $45,5 \%$ ) e para o Rio de Janeiro o comércio varejista $(46,4 \%)$. O comércio varejista está mais ligado às atividades de consumo final, e o comércio por atacado, mais ligado às atividades industriais, logo o peso relativo maior do comércio varejista no Rio era esperado, devido às características fluminenses já apontadas para o setor de serviços como um todo.

A evolução do comércio para as três economias, no período 2003-2007, é positiva em termos de taxas de crescimento anuais da RBR. Em termos das taxas médias de crescimento anuais da mesma variável, o Rio de Janeiro apresenta o pior resultado: $11,8 \%$ contra mais de $14 \%$ para o Brasil e São Paulo. Entretanto, o comportamento das taxas de crescimento anuais foi positivo e crescente no período para o ERJ, enquanto no Brasil e no ESP elas se mostraram mais instáveis, crescendo em 2004 e 2005 e decrescendo em 2006 e 2007, apesar de não se tornarem negativas.

Em termos de PO, entre 2003 e 2007, o mesmo resultado de taxas de crescimento positivas, nas três economias, pôde ser observado. O Brasil é o único a apresentar uma trajetória expansiva até 2006, repetindo o resultado desse ano em 2007. O ERJ e o ESP têm um desempenho em 
termos de $\mathrm{PO}$ menos sustentado. O primeiro tem forte redução de suas taxas de crescimento anuais nos anos de 2005 e 2006, em relação a 2004 (de $9,6 \%$ para $2,3 \%$ e $3,4 \%$ ) e a maior taxa de crescimento em 2007 $(12,5 \%$ contra $9,8 \%$ e $8,6 \%)$. O segundo cresceu muito pouco em 2004 $(0,1 \%)$ e, ao contrário do ERJ, teve um ótimo desempenho em 2005 $(11,4 \%)$ e 2006 (13\%), declinando um pouco em 2007 (8,6\%).

O resultado do desempenho das taxas de crescimento anuais da RBR do comércio foi o seu crescimento acumulado entre 1996 e 2007 de mais de $57 \%$ ou mais para o Brasil e São Paulo e de pelo menos 10 p.p. inferior para o Rio de Janeiro $(47,1 \%)$. O grande vilão desse resultado foi o comércio varejista fluminense, que cresceu a uma taxa média anual de $7,2 \%$ contra a do Brasil de $12,7 \%$ e a de São Paulo de $12,8 \%$. Neste período o comércio por atacado no ERJ foi quem mais contribuiu para a recuperação de sua trajetória passada negativa apresentada na primeira seção.

Em termos de PO, o desempenho foi também diferenciado e pior para a economia fluminense, ainda que menos distinto das demais economias do que em termos de RBR, já que o comércio por atacado, principal responsável pelo baixo crescimento acumulado da RBR, é menos intensivo em $\mathrm{PO}$ do que o comércio varejista. A diferença percentual das taxas médias de crescimento de PO entre Brasil e São Paulo, de um lado, e o Rio de Janeiro, de outro, no período, foi de apenas 2 p.p. contra a diferença de 3 p.p. para a RBR.

As mudanças estruturais na atividade de comércio nas três economias podem ser observadas através da participação relativa dos subsetores, em termos de RBR entre 2003 e 2007 (ver Tabela 4). Ao longo do período considerado, os subsetores de comércio varejista de cada economia perdem participação relativa, e os subsetores de comércio de veículos e combustíveis ganham posição. O subsetor de comércio atacadista volta a ganhar participação relativa na economia fluminense e perde nas economias do Brasil e de São Paulo. Em 2003, o comércio atacado representava $35,9 \%$ da RBR do comércio fluminense, passando a representar $41,5 \%$, em 2007. Já quanto ao comércio varejista, percebe-se uma redução de seu peso relativo: de $53 \%$ para $46,4 \%$, enquanto a RBR do comércio de veículos e combustíveis expandiu-se em 1 p.p.

Em termos de $\mathrm{PO}$, o comércio varejista é o mais importante em peso relativo nas três economias, representando $70 \%$ ou mais de participação relativa no emprego gerado pela atividade de comércio, sendo o ERJ o 
Tabela 4

Estrutura do Comércio Brasileiro, Fluminense e Paulista por Subsetores (\%): RBR e PO, 2003 e 2007

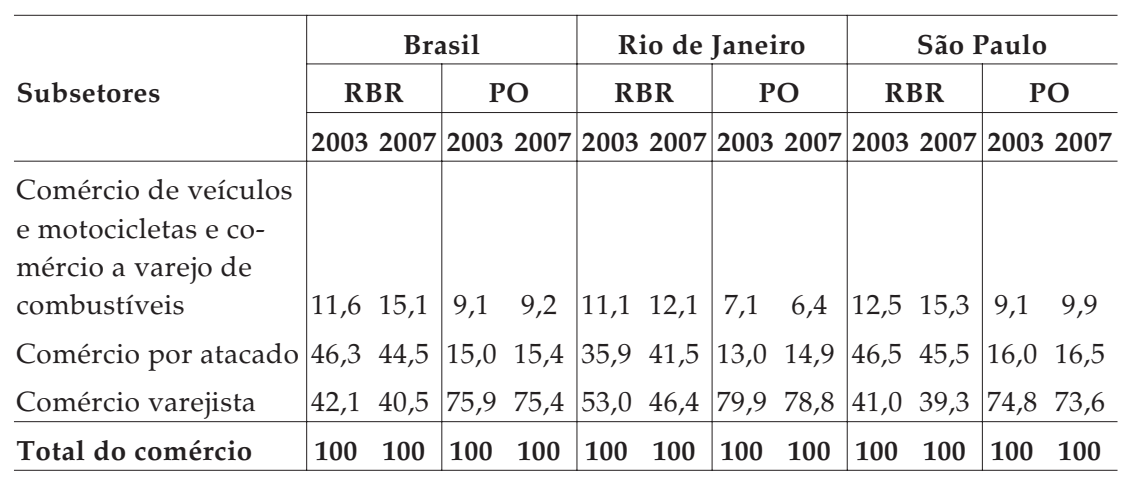

Fonte: Elaborado pelo Grupo de Economia da Inovação (IE/UFRJ) com base na Pesquisa Anual do Comércio, IBGE $(2003,2007)$.

que apresenta a maior proporção. No período entre 2003 e 2007, a importância relativa desse comércio decresceu menos para o Brasil e mais para o ERJ e ESP. A segunda atividade mais importante em termos relativos de geração de emprego é o comércio por atacado, que teve a sua importância relativa aumentada no período, com mais intensidade para o ERJ (1.9 p.p. contra apenas 0.5 p.p. para as demais economias). Finalmente, a importância de geração de empregos no comércio de veículos cresceu no Brasil e em São Paulo e decresceu no Rio de Janeiro.

A participação relativa do comércio do Rio e de São Paulo na atividade de comércio brasileira em termos de RBR, entre 2003 e 2007, mostra uma perda de 0.7 p.p. para a economia fluminense (de 9,8\% do PIB de comércio brasileiro para $9,1 \%$ ) e um ganho 0.2 p.p. na economia paulista, que mantém sua participação relativa na atividade de comércio brasileira em torno de $35 \%$. O tamanho relativo do comércio do ERJ é inferior a quase quatro vezes o comércio paulista na economia brasileira. Em termos de PO, tanto o Rio de Janeiro quanto São Paulo perdem participação relativa no emprego gerado pelo comércio brasileiro de 0.5 p.p.

\section{As Perspectivas Conjunturais da Economia Fluminense e os Investimentos em Curso}

Uma observação metodológica importante e que justifica a criação desta seção foi a mudança de metodologia da Classificação Nacional de Atividades Econômicas (Cnae) em 2007, passando a ser utilizada, 
em 2008, a versão 2.0 dessa Classificação, em vez da versão 1.0, utilizada no período entre 1996 e 2007. Para o ano de 2007, o IBGE já fez a correspondência entre as duas versões da Classificação, entretanto, ela não está disponível para o ano de 2008. Nesta subseção especula-se sobre as tendências que se pode inferir dos dados para os anos de 2008 e 2009, comparando-os com o ano de 2007, cujos dados já foram convertidos para a nova classificação Cnae 2.0. Adicionalmente, utilizaram-se as pesquisas conjunturais do IBGE, que podem estar antecipando hipóteses sobre tendências acerca da evolução do produto real da indústria (PIM-PF) e do volume de vendas do comércio varejista (PMC), como indicadores de tendências projetadas até 2010. Outras publicações que tratam do desenvolvimento econômico do Rio de Janeiro, utilizando-se de outros dados que não as pesquisas do IBGE, também foram consultadas.

A tendência para a indústria entre 2008 e 2009, em relação ao ano de 2007, em termos de VBPI, é continuar crescendo, mas a taxas maiores do que as taxas médias apresentadas no período anterior para o Brasil e para o Rio de Janeiro. Contudo, a taxa registrada para São Paulo é menor do que a taxa média do período anterior, indicando uma maior desaceleração na economia paulista. Porém, em 2009, em função da crise financeira internacional, as taxas de crescimento foram negativas, em torno de mais de 3,5\% para o Brasil e o ESP e, ainda que também negativas para o ERJ, apenas em $2 \%$, indicando que o retardo nas decisões de investimento, comum nos períodos de crise, afetaram menos a indústria no Rio do que as brasileira e paulista. Por outro lado, quando se analisam os números de $\mathrm{PO}$ na indústria total, a taxa de crescimento é positiva, mesmo em 2009, para as três economias. De fato, verifica-se uma taxa média de crescimento (2008-2009) de 3\% para o Brasil, 5\% para o ERJ e $2 \%$ para o ESP. Em resumo, o desempenho da economia fluminense é destacado, portanto, nos anos mais recentes, tanto em termos de VBPI, quanto no emprego na indústria.

Considerando a pesquisa conjuntural da indústria, índice de produção física, observa-se que a crise internacional de setembro de 2008 refletiu mais na economia paulista do que nas economias brasileira e fluminense, respectivamente queda de 11 p.p. para o índice de produção física em São Paulo, 9 p.p. para o Brasil e apenas 4 p.p. para o Rio (ver Gráfico 2). Isso confirma mais uma vez que o desempenho conjuntural fluminense pode ser explicado pela manutenção dos investimentos con- 
Gráfico 2

Evolução do Índice do Produto Real da Indústria Geral (ano base 1996)

(1995-2010)

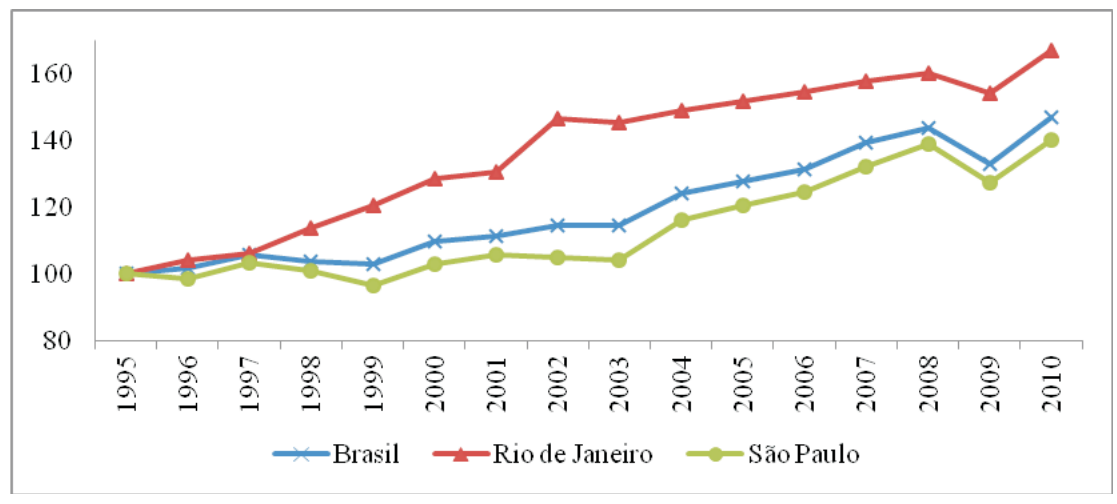

Fonte: Elaborado pelo Grupo de Economia da Inovação (IE/UFRJ) com base na Pesquisa Industrial Mensal - Produção Física, IBGE (1995-2010).

tratados e o seu não adiamento na economia do Rio, diferentemente das demais economias.

O comportamento conjuntural, entre 2008 e 2009, do setor de serviços foi distinto do setor industrial, já que apresentou crescimento constante nesses anos de sua RBS. A tendência do setor de serviços fluminense para 2008, em relação ao ano anterior, em termos de RBS, é dois pontos percentuais inferior ao desempenho da mesma variável para o Brasil e o ESP (15\% contra 17\%). Ou seja, as três economias aceleram a taxa anual de crescimento em relação ao período anterior cerca de 10 p.p.; em relação à taxa média de crescimento anual, a taxa de crescimento apresentada pelo Rio de Janeiro, entretanto, ainda é inferior. Já em 2009, há uma reação do setor de serviços fluminense que cresce mais do que aqueles do Brasil e de São Paulo, em termos de RBS.

As tendências do setor de comércio mostram uma taxa média de crescimento da RBV positiva para os anos 2008 e 2009 nas três economias. O ERJ cresce a taxas médias superiores às do Brasil e do ESP (10 contra $8,8 \%$ e $7,4 \%$ respectivamente). O expressivo crescimento do comércio no ERJ deve-se ao crescimento da RBV em 2008 (crescimento de 14\% em relação a 2007). Comparadas com as taxas médias de crescimento do período 2003-2007, observa-se, todavia, uma desaceleração do crescimento nas três economias, sendo em menor intensidade no ERJ. Por outro lado, quando analisados os dados de PO, verifica-se que o ERJ 
cresceu a uma taxa média de 5,2\%, em 2008-2009, menor do que a do Brasil e a do ESP, de $10 \%$ para ambos.

Para inferir as tendências mais recentes no setor de comércio, pode-se contar também com a pesquisa conjuntural sobre o índice do volume de vendas do comércio varejista entre 2000 e 2010, considerando o ano de 2000 como o ano-base (ver Gráfico 3). Este pode ser um bom indicador da atividade econômica, já que infere a tendência das vendas no comércio varejista e mostra o comportamento antecedente do consumidor. $\mathrm{O}$ volume de comércio varejista fluminense é decrescente entre 2000 e 2003 e crescente no período entre 2004 e 2010, com um pequeno arrefecimento em 2009. De uma forma geral, as economias do Brasil e de São Paulo seguem esta mesma tendência do volume de vendas do comércio varejista. A diferença entre as três economias pode ser notadamente marcada a partir de 2004, quando se observa um crescimento mais acelerado do comércio brasileiro em relação ao do Rio e de São Paulo. Em 2007, entretanto, o comércio varejista de São Paulo ultrapassa o do Rio de Janeiro e acompanha o crescimento do brasileiro. A taxa média de crescimento observada no período é de 3,8\% para o Rio, contra 4,9\% para o Brasil e 5,1\% para o São Paulo. Em outras palavras, as expectativas no Rio de Janeiro a partir do indicador do volume de vendas do comércio varejista ainda não são as melhores.

Dois indicadores adicionais do crescimento econômico recente, relacionados ao crescimento dos investimentos produtivos, entretanto,

\section{Gráfico 3}

Evolução do Índice de Volume de Vendas do Comércio Varejista (ano base 2000) (2000-2010)

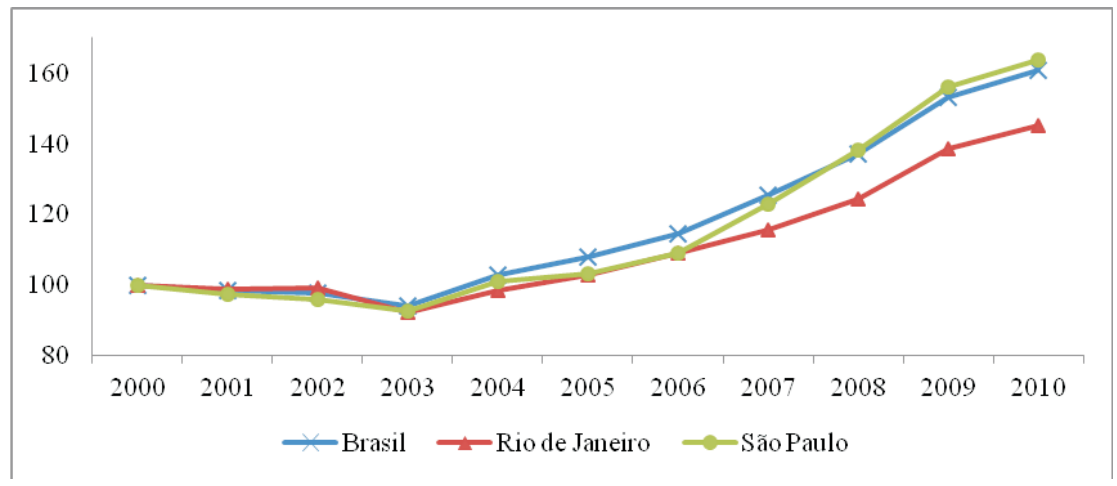

Fonte: Elaborado pelo Grupo de Economia da Inovação (IE/UFRJ) com base na Pesquisa Mensal do Comércio, IBGE (2000-2010). 
apontam melhores perspectivas para a economia fluminense: a elevação dos investimentos financiados pelo BNDES no Rio de Janeiro, de R \$ 16 bilhões no período 2003-2006 para R 52 bilhões em 2007-2010, avançando $230 \%$ contra um crescimento de apenas $138 \%$ na média nacional; e o crescimento do emprego formal que cresceu entre estes dois quadriênios $42 \%$ contra $31 \%$ na média nacional (Bueno e Casarin, 2011).

As principais vocações do ERJ e que lideram os investimentos contratados dão destaque nacional à economia fluminense e reforçam vocações estruturais de disponibilidade de recursos naturais ou indústrias já existentes. As informações sobre os investimentos contratados em várias áreas, a seguir, foram obtidas em Bueno e Casarin (2011). Na área de exploração e produção de petróleo, o Rio de Janeiro é responsável por $80 \%$ da produção nacional e, na área de exploração e produção de gás, por $46 \%$. Os novos investimentos contratados pela Petrobras e outras empresas privadas monta a $\mathrm{R} \$ 83$ bilhões para o período 2010-2012.

$\mathrm{Na}$ área de siderurgia, o novo investimento realizado pela ThyssenKrup CSA Companhia Siderúrgica do Atlântico, em Santa Cruz, zona oeste do município, coloca o Rio de Janeiro como segundo produtor de aço do país, atrás apenas de Minas Gerais, somando-se à liderança histórica que a Companhia Siderúrgica Nacional (CSN) representou na área de siderurgia. Os investimentos montam a R $\$ 18$ bilhões.

$\mathrm{Na}$ área de refino de petróleo e petroquímica, o Rio de Janeiro já produz 12\% do petróleo nacional a partir das refinarias Duque de Caxias (Reduc), da Petrobras, e Manguinhos. Espera-se o investimento em uma nova refinaria, associada a uma unidade petroquímica, investimentos da Petrobras no denominado Complexo Petroquímico do Estado do Rio de Janeiro (Comperj), localizada em Itaboraí. Estes investimentos vêm se somar a Rio Polímeros S.A. (Riopol), localizada em Duque de Caxias, de propriedade da Quattor e recentemente adquirida pela Brasken.

$\mathrm{Na}$ área da indústria naval, o impulso dos investimentos da Petrobras e sua política de compras com incentivo à produção nacional, associado a outros investimentos de portos, estão permitindo que o Rio retome a sua histórica posição de berço da indústria naval. Estão previstos para o período 2010-2012 cerca de $\mathrm{R} \$ 5$,3 bilhões de investimentos. Estes investimentos foram conquistados graças ao conhecimento acu- 
mulado na indústria, disponibilidade de mão de obra qualificada, pela proximidade dos principais fornecedores de peças para a indústria naval e também dos grandes compradores.

$\mathrm{Na}$ área de logística e serviços off-shore, destacam-se os investimentos em terminais portuários da LLX, Usiminas, Petrobras, CSN e Gerdau, visando a exportação de minério de ferro. Associado a esses investimentos, crescerão as operações de carga realizadas pelas empresas investidoras e também a necessidade de instalação de centros de distribuição. Se os primeiros investimentos em terminais geram poucos empregos diretos, praticamente nenhum imposto (isento de ICMS) e grandes impactos ambientais, os segundos (operações de carga e centros de distribuição) são de grande interesse do ERJ pela capacidade de reverterem a perda observada nas atividades de comércio e serviços fluminenses e pelo potencial de geração de empregos diretos.

Finalmente, a construção do Complexo do Açu, localizado no município de São João da Barra, norte do ERJ, que reforça a interiorização do crescimento no Rio. Trata-se de um conjunto de empreendimentos na área de infraestrutura (mineroduto) associado a investimentos industriais (usinas termoelétricas, siderurgias e estaleiro).

Em resumo, parece que o Rio de Janeiro apresenta uma ótima conjuntura de retomada dos investimentos e de não desaceleração após a crise econômica de 2008. Todos os indicadores conjunturais apontam nesta direção. Há suficientes investimentos em andamento e excelentes perspectivas para que eles dinamizem outros segmentos do Rio em direção a um novo ciclo virtuoso de desenvolvimento.

\section{CONSIDERAÇÕES FINAIS: ESTARIAM AS VOCAÇÕES DO ESTADO DO RIO DE JANEIRO EM TRANSIÇÃO?}

As mudanças marcantes e que afetaram a economia fluminense podem ser resumidas em três: a descentralização da indústria do município do Rio de Janeiro (metrópole) para o interior do Estado; a incapacidade das indústrias tradicionais atraírem novos investimentos complementares que as tornassem mais dinâmicas e a perda da importância relativa do setor de serviços, uma das grandes vocações do Rio. As externalidades negativas nas áreas de segurança e transporte urbano e a transferência da capital para Brasília são algumas das causas que poderiam ser arroladas para as duas mudanças registradas, mas o evento decisivo para explicá-las foi o crescimento da indústria extrativa baseada em 
petróleo e gás na bacia de Campos, deslocando o crescimento para o interior.

Essas mudanças levaram à forte reestruturação das atividades econômicas no período entre 1996 e 2007. Na indústria, cresce a importância da indústria extrativa a expensas da indústria de transformação. Nos serviços, diminui a importância dos serviços prestados às empresas em benefício do crescimento dos serviços prestados às famílias. No comércio, reduz-se a importância do comércio atacadista em prol do varejista. O resultado é que a economia fluminense torna-se menos dinâmica do que as economias brasileira e paulista, o que se reflete em suas menores taxas de crescimento no período e redução de sua contribuição para a formação de riqueza do país. Ainda que essa perda seja maior em termos de resultados econômicos (VBPI, RBS, RBR) do que em termos de pessoal ocupado.

Os investimentos industriais em curso, destacados na seção anterior, reforçam vocações anteriores do estado e são ainda incapazes de emprestar um dinamismo maior à economia fluminense. Além disso, o Rio de Janeiro possuía uma vocação muito forte também em serviços prestados às grandes empresas públicas e ao funcionamento administrativo da capital. A mudança da capital para Brasília nos anos 1960 e a posterior abertura econômica dos anos 1990, somada à privatização das empresas estatais, mudaram completamente este quadro e mesmo os novos investimentos em infraestrutura não foram capazes de retomar aquela vocação em serviços. Interessa, a guisa de considerações finais, especular em que medida poder-se-á construir novas vocações para o ERJ, por meio de uma política de desenvolvimento capaz de alavancar o crescimento de outras indústrias encadeadas e já presentes no estado, tais como a automobilística e a metal mecânica, que trouxessem maior dinamismo para a indústria produtora de bens intermediários com agregação de valor e atraíssem novos investimentos da indústria do conhecimento. As potencialidades do ERJ que permitem especular com as possibilidades destes novos investimentos na indústria do conhecimento são a sua liderança em várias áreas de pesquisa e desenvolvimento. Destacam-se as áreas de engenharia (Coppe/UFRJ), óleo e gás (Cenpes), saúde (Fiocruz) e energia (Cepel), todas referência na formação de mão de obra qualificada no Brasil.

Estas potencialidades podem ser aproveitadas pelo Rio para agregar valor aos investimentos em curso. Um exemplo é o investimento que 
está sendo realizado no Parque Tecnológico do Fundão. Com as oportunidades oferecidas pelo pré-sal, desponta, desde 2003, na ilha do Fundão, o Parque Tecnológico, que tem por objetivo aumentar a riqueza de conhecimento por meio da promoção da cultura, inovação e competitividade das empresas e instituições baseadas no conhecimento que lhes é associado. Também estimula e gerencia o fluxo de conhecimentos e de tecnologias entre universidades, instituições de pesquisa e desenvolvimento, empresas e mercados; facilita a criação e o crescimento de empresas baseadas na inovação através da incubação e de processos de spin-off; e fornece outros serviços de valor agregado bem como espaços e serviços de apoio de elevada qualidade. Em 2007, o Parque Tecnológico recebeu o Cenpes e, a partir deste, possibilidades de criação de novas empresas de base tecnológica, transferência de tecnologias e instalação de laboratórios especiais da UFRJ, além de maior competitividade das empresas instaladas, gerando também estímulo à atitude empreendedora dos estudantes etc.

O Parque é considerado o quarto maior do mundo em extensão. Empresas estrangeiras importantes como a FMC Technology, a Baker Hughes (ambas americanas), a Schlumberger (franco-americana) e a Halliburton (americana) já instalaram ou têm instalações previstas no local. A unidade da Baker Hughes será dedicada ao desenvolvimento de estudos para a construção de poços de petróleo, a FMC conduzirá projetos de pesquisa de tecnologias submarinas e a Schlumberger desenvolverá atividades ligadas ao desenvolvimento de tecnologias de sísmica e caracterização de reservatórios de petróleo. Por último, a Halliburton, que desenvolve tecnologias para aumentar o desempenho dos poços através de softwares de visualização em 3D.

Está prevista também a instalação de um centro de pesquisa da Usiminas dedicado à inovação para o setor de metalurgia e siderurgia que, em sua fase inicial, atenderá as demandas do pré-sal de aços resistentes à corrosão. Da mesma forma, está prevista a instalação do centro de pesquisa da General Eletric (o maior de todos os investimentos), que será focado em tecnologias altamente avançadas para as indústrias de óleo e gás, energias renováveis, mineração, transporte ferroviário e aviação. Outro empreendimento é a expansão do Parque Tecnológico visando espaço na ilha de Bom Jesus, hoje em área militar na ilha do Fundão. 
Para os próximos três anos, estão previstos mais de R $\$ 1,2$ bilhão de investimentos na área do Parque e criação de mil novos empregos altamente qualificados. Até 2017, são estimadas 22 empresas, 30 em lotes individuais, 50 em incubadoras, 140 em prédios compartilhados com foco em energia e meio ambiente. Enfim, os novos investimentos previstos e o conjunto de novos investimentos em andamento são bastante promissores. Entretanto, como visto, eles ainda não se refletem nos indicadores estruturais de desempenho analisados até 2007.

A análise de algumas tendências conjunturais, todavia, indica que o crescimento apresentado até 2007 tenderá a se ampliar até 2012. Seja porque os dados conjunturais entre 2008 e 2009 continuam positivos, ainda que tenha havido uma pequena desaceleração, seja porque o conjunto de investimentos em andamento sustentarão ou até ampliarão essas perspectivas. Resta saber se elas serão uma realidade em futuro próximo e se o Rio de Janeiro poderá finalmente dizer que o seu dinamismo mais moderado do que o do Brasil e do ESP, entre 1996 e 2007, é uma trajetória passada, ou estará fadado a continuar apresentando taxas de crescimento inferiores e perdendo participação relativa na criação da riqueza nacional graças às características estruturais de sua economia.

(Recebido para publicação em outubro de 2011)

(Versão reapresentada em maio de 2012)

(Aprovado para publicação em junho de 2012) 


\section{REFERÊNCIA BIBLIOGRÁFICA}

BNDES (Banco Nacional de Desenvolvimento Econômico e Social). (2011a), "Perspectivas de Investimentos na Indústria 2011-2014". Visão do Desenvolvimento, № 91.

(2011b), "Perspectivas de Investimentos em Infraestrutura 2011-2014". Visão do Desenvolvimento, no 92.

BUENO, Júlio C. C. e CASARIN, Luiz Octavio B. (2011), “Os Recursos para o Petróleo e as Perspectivas para o Investimento no Estado do Rio de Janeiro", in A. Urani e F. Giambiagi (orgs.), Rio: A Hora da Virada. Rio de Janeiro, Elsevier, pp. 40-50.

DINIZ, Célio Campolina. (1993), “Desenvolvimento Poligonal no Brasil: Nem Desconcentração, nem Contínua Polarização". Nova Economia, vol. 3, no 1, pp. 35-64.

. (2000), “Impactos Territoriais da Reestruturação Produtiva”, in L. C. de Q. Ribeiro (org.), O Futuro das Metrópoles: Desigualdades e Governabilidade. Rio de Janeiro, Editora Revan, pp. 21-61.

. (2002), “A Nova Configuração Urbano-Industrial no Brasil”, in A. Kon (org.), Unidade e Fragmentação: A Questão Regional no Brasil. São Paulo, Editora Perspectiva, Col. Debates.

FAURÉ, Yves-A. e HASENCLEVER, Lia (orgs.). (2005), O Desenvolvimento Local no Estado do Rio de Janeiro: Estudos Avançados nas Realidades Municipais. Rio de Janeiro, E-Papers Serviços Editoriais.

e SILVA NETO, Romeu e. (orgs.). (2008), Novos Rumos para a Economia Fluminense: Oportunidades e Desafios do Crescimento do Interior. Rio de Janeiro, E-Papers Serviços Editoriais.

HASENCLEVER, Lia e MAEDA, Isleide. (2007), “La Evolución de las Configuraciones Productivas Locales en Brasil: Tendencias y Interpretaciones", in M. E. Ignez e P. Labazé (coords.), Globalización y Localidad: Espacios, Actores, Movilidades e Identidades. México, Centro de Investigaciones y Estudios Superiores en Antropologia Social, Institut de Recherche pour le Developpement, pp. 121-142.

IBGE (Instituto Brasileiro de Geografia e Estatística). Contas Regionais 1996-2008. Rio de Janeiro, IBGE.

. Pesquisa Anual de Serviços 2002-2007. Rio de Janeiro, IBGE.

. Pesquisa Anual de Serviços 2007-2009. Rio de Janeiro, IBGE.

. Pesquisa Anual do Comércio 2003-2007. Rio de Janeiro, IBGE.

. Pesquisa Anual do Comércio 2007-2009. Rio de Janeiro, IBGE.

. Pesquisa Industrial Anual Empresa 1996-2007. Rio de Janeiro, IBGE.

. Pesquisa Industrial Anual Empresa 2007-2009. Rio de Janeiro, IBGE.

. Pesquisa Industrial Mensal: Produção Física 1995-2010. Rio de Janeiro, IBGE.

. Pesquisa Mensal do Comércio 2000-2010. Rio de Janeiro, IBGE.

JACOBS, Jane. (1970), The Economy of Cities. New York, Vintage Books.

. (1984), Cities and the Wealth of Nations: Principles of Economic Life. New York, Random House. 
Lia Hasenclever, Julia Paranhos e Ricardo Torres

KON, Anita. (2004), Economia de Serviços: Teoria e Evolução no Brasil. Rio de Janeiro, Editora Elsevier.

THE ECONOMIST. (2011), “Doing Business in Brazil: Rio or São Paulo?” Disponível em http: www.economist.com. Acessado em 15 de setembro.

URANI, André. (2008), Trilhas para o Rio: Do Reconhecimento da Queda à Reinvenção do Futuro. Rio de Janeiro, Elsevier. 


\section{ABSTRACT \\ The Economic Performance of Rio de Janeiro: Background and Prospects}

The article analyzes the structural and contextual dynamics of the Rio de Janeiro State economy from 1996 to 2009 in order to verify whether recent investments will be capable of turning such dynamics into a new virtuous investment cycle. The State's economy was compared to those of Brazil as a whole and São Paulo State. The main finding was that the State of Rio de Janeiro underwent an extensive restructuring of its economy and made a major contribution to Brazil's national wealth. Less dynamic activities (in terms of economic results) gained ground, like the extractive industries, services to families, and retail commerce. However, the State has still failed to glimpse a new economic vocation.

Key words: economic performance; structural change; Rio de Janeiro State; Brazil

\section{RÉSUMÉ \\ Performance Économique de Rio de Janeiro: Trajectoires Passées et Perspectives Futures}

Cet article analyse les dynamiques structurelles et conjoncturelles de l'économie de l'État de Rio de Janeiro entre 1996 et 2009 avec pour objectif de vérifier dans quelle mesure les investissements récents auront ou non la condition de transformer ces dynamiques en direction d'un nouveau cycle d'investissement vertueux. On a utilisé la méthode comparative para rapport à deux économies: celle du Brésil et celle de São Paulo. Le principal résultat observé est que l'État de Rio est passé par une forte restructuration de ses activités économiques, ce qui a contribué à la richesse nationale. Certaines activités moins dynamiques du point de vue des résultats économiques telles que l'industrie liée à l'extraction, les services à la famille ou le commerce de détail ont gagné de l'espace. Mais on ne voit toutefois pas pointer une nouvelle vocation.

Mots-clés: performance économique; changement structurel; État de Rio de Janeiro; Brésil 